\title{
Studi Penilaian Ekosistem Mangrove Hasil Tanam Berdasarkan Keberadaan Gastropoda di Pulau Pramuka, Kepulauan Seribu, Jakarta
}

\author{
Yayan Mardiansyah Assuyuti ${ }^{\mathrm{a}, \mathrm{b}_{*}}$, Alfan Farhan Rijaluddin ${ }^{\mathrm{a}}$ \\ ${ }^{a}$ Program Studi Biologi, Fakultas Sains dan Teknologi, UIN Syarif Hidayatullah Jakarta, Jalan Ir. H. Juanda No. 95 Ciputat, Tangerang Selatan, \\ Banten 15412, Indonesia \\ ${ }^{b}$ Laboratorium Ekologi, Pusat Laboratorium Terpadu, UIN Syarif Hidayatullah Jakarta, Jalan Ir. H. Juanda No. 95 Ciputat, Tangerang Selatan, \\ Banten 15412, Indonesia \\ * Penulis koresponden. Tel.: +62-812-8375-3305 \\ Alamat e-mail: ymar.assuyuti@uinjkt.ac.id \\ Diterima (received) 15 Oktober 2016; disetujui (accepted) 21 November 2016; tersedia secara online (available online) 23 November 2016
}

\begin{abstract}
The aims of mangrove replanted are to protect and good quality of coastal ecosystems and small islands, but it is have influenced to change of habitat and ecology function. This study conducted at Pramuka Island, Seribu islands, Jakarta, in June 2016. Data of gastropoda using $1 \mathrm{~m}^{2}$ square random sampling and divide depend on height are 0-1, 1-2 and 2-3 m. The aims of study are to determine (i) diversity, density, (ii) vertical distribution, (iii) size shell, (iv) correlation of density with distribution, (v) correlation of size shell with vertical distribution, (vi) correlation of individual with height gastropoda, and (vii) assessment of mangrove replanted depend on gastropoda. The species of Terebralia sp. and Littorina sp. are found in mangrove replanted. The total value of diversity and density of mangrove gastropoda are 0.6 and $31.3 \mathrm{ind} / \mathrm{m}^{2}$, respectively. Vertical distribution of gastropoda Terebralia $\mathrm{sp}$. found in $0-1$ $\mathrm{m}$ and Littorina sp. in 0-3 m. The density and individual of Terebralia sp. have high value and size shell largest than Littorina sp. Gastropoda found indicated that the mangrove ecosystem in Pramuka island is still young and is in a transition state.
\end{abstract}

Keywords: Mangrove; Pramuka island; Diversity; Density; Vertical Distribution

\begin{abstract}
Abstrak
Penanaman mangrove bertujuan menjaga dan memperbaiki kualitas ekosistem pesisir dan pulau-pulau kecil secara berkelanjutan, akan tetapi memiliki dampak terhadap perubahan fungsi habitat dan ekologi. Penelitian ini dilakukan di pulau Pramuka, kepulauan Seribu, Jakarta pada bulan Juni 2016. Pengambilan data gastropoda menggunakan kuadrat $1 \mathrm{~m}^{2}$ secara acak dan membagi berdasarkan ketinggian yaitu 0-1, 1-2 dan 2-3 m. Tujuan dari penelitian ini adalah mengetahui (i) keanekaragaman, kepadatan, (ii) distribusi vertikal, (iii) ukuran cangkang, (iv) hubungan antara kepadatan dengan distribusi, (v) hubungan antara ukuran cangkang dengan distribusi vertikal, (vi) hubungan jumlah individu gastropoda terhadap ketinggian, dan (vii) penilaian ekosistem mangrove hasil tanam berdasarkan keberadaan gastropoda. Spesies yang ditemukan di ekosistem mangrove hasil tanam adalah Terebralia sp. dan Littorina sp. Keanekaragaman dan kepadatan gastropoda mangrove tanam memiliki nilai total 0.6 dan $31.3 \mathrm{ind} / \mathrm{m}^{2}$, secara berurutan. Distribusi vertikal gastropoda yang paling banyak ditemukan di ketinggian 0-1 m dengan jenis Terebralia sp. dan jenis yang ditemukan di ketinggian 0-3 m adalah Littorina sp. Jenis Terebralia sp. memiliki kepadatan dan individu yang tinggi dan ukuran cangkang yang paling panjang dibandingkan dengan Littorina sp. Berdasarkan keberadaan gastropoda menunjukkan bahwa ekosistem mangrove di pulau Pramuka tergolong muda dan masih dalam masa transisi.
\end{abstract}

Kata Kunci: Mangrove; Pulau Pramuka; Keanekaragaman; Kepadatan; Distribusi Vertikal

\section{Pendahuluan}

Ekosistem mangrove memiliki fungsi yang penting untuk makhluk hidup di daratan dan perairan (Kathiresan dan Bingham, 2001; Hogarth, 2007; Nagelkerken et al., 2008). Fungsi mangrove sebagai pusat kegiatan masyarakat, daur biogeokimia dan ekologi yang saling mempengaruhi satu sama lain (Field et al., 1998). Ekosistem mangrove mengalami penurunan dalam beberapa dekade terakhir (Polidoro et al., 2010) yang disebabkan oleh eksploitasi besar-besaran (Hogarth, 2007) seperti pembukaan lahan untuk pengembangan pesisir dan budidaya, penggunaan bahan baku kayu dan bahan bakar (Polidoro et al., 2010). Wilayah Indonesia adalah salah satu daerah yang mengalami penurunan mangrove sekitar 20,7 sampai 22,7 $\mathrm{km}^{2}$ (Daru et al., 2013). Penurunan ekosistem mangrove akan berdampak pada hilangnya komunitas makrofauna yang menghuni ekosistem tersebut.

Menghambat laju deforestrasi dan meningkatkan rehabilitasi mangrove yang ada mungkin akan menghambat punahnya jenis dari gastropoda, krustasea dan sponge (Ellison, 2008). Penelitian Gorman dan Turra (2016), menunjukkan usaha penanaman kembali hutan mangrove memberikan hasil yang positif, dimana terdapat peningkatan kelimpahan dan keanekaragaman komunitas makrofauna. Sehingga, reboisasi merupakan cara untuk meningkatkan pemulihan alam, meningkatkan 
keanekaragaman dan mengembalikan fungsi ekosistem di pantai dan daerah estuari.

Rehabilitasi mangrove dilakukan dengan penanaman sederhana tanpa memperhitungkan cukupnya luas area atau evaluasi berkelanjutan mengenai kesuksesan rehabilitasi pada tingkat ekosistem (Field, 1996). Hal ini memiliki dampak terhadap perubahan habitat dan fungsi ekologis pada mangrove hasil tanam dibandingkan hutan mangrove alami (Bosire et al., 2008). Jumlah moluska merupakan salah satu biota yang mengalami dampak terhadap rehabilitasi mangrove dan dapat dijadikan alat untuk penilaian habitat mangrove yang baru ditanam (Bosire et al., 2008; Macintosh et. al., 2002). Suksesi mangrove yang ditanam berpengaruh terhadap jumlah, keanekaragaman (Ernawati dkk., 2013) dan kekayaan (Gorman dan Turra, 2016) spesies moluska dan krustacea. Berdasarkan uraian tersebut, tujuan dari penelitian ini adalah mengetahui (i) keanekaragaman, kepadatan, (ii) distribusi vertikal, (iii) ukuran cangkang, (iv) hubungan antara kepadatan dengan distribusi, (v) hubungan antara ukuran cangkang dengan distribusi vertikal, (vi) jumlah individu gastropoda terhadap ketinggian, dan (vii) penilaian ekosistem mangrove hasil tanam berdasarkan keberadaan gastropoda di pulau Pramuka, kepulauan Seribu, Jakarta.

\section{Metode Penelitian}

\subsection{Lokasi Penelitian}

Pulau Pramuka adalah salah satu pulau yang berada di wilayah kepulauan Seribu, Jakarta dengan luas 16 Ha dan termasuk kedalam zona pemukiman dengan jumlah penduduk 1.004 jiwa (BPS, 2015). Saat ini pemerintah daerah di pulau Pramuka sedang melakukan rehabilitasi mangrove pada bagian timur pulau dengan tujuan untuk menahan abrasi pantai. Jenis mangrove yang ditanam adalah Rhizophora stylosa.

\subsection{Prosedur Penelitian}

Penelitian ini dilakukan pada bulan Juni 2016 di pulau Pramuka, kepulaun Seribu, Jakarta (Gambar 1). Pengambilan data gastropoda dilakukan pada saat surut terendah dengan membuat plot dengan ukuran $1 \mathrm{x} 1 \mathrm{~m}^{2}$ secara acak pada daerah hutan mangrove tanam. Gastropoda dikelompokkan berdasarkan ketinggian dari dasar sedimen yaitu 0-1 m, 1-2m, 2-3m. Sampel kemudian diawetkan dengan menggunakan alkohol $96 \%$ dan di bawa ke Pusat Laboratorium Terpadu (PLT) Universitas Islam Negeri (UIN) Syarif Hidayatullah Jakarta untuk identifikasi. Dilakukan pengukuran cangkang gastropoda yang ditemukan meliputi panjang total, lebar total, panjang aperture, dan lebar aperture. Identifikasi gastropoda mengacu pada buku panduan Dharma (1988), Abbott dan Dance (1986) dan Poutiers (1998).

\subsection{Analisis Data}

Perbedaan jumlah gastropoda di masing-masing ketinggian dianalisis dengan one-way analysis of variance (ANOVA). Hubungan antara kepadatan dengan distribusi dan hubungan antara ukuran cangkang dengan distribusi vertikal gastropoda dianalisa menggunakan regresi linear. Analisis ANOVA menggunakan SPSS versi 21, sedangkan regresi linear menggunakan Microsoft Excel.

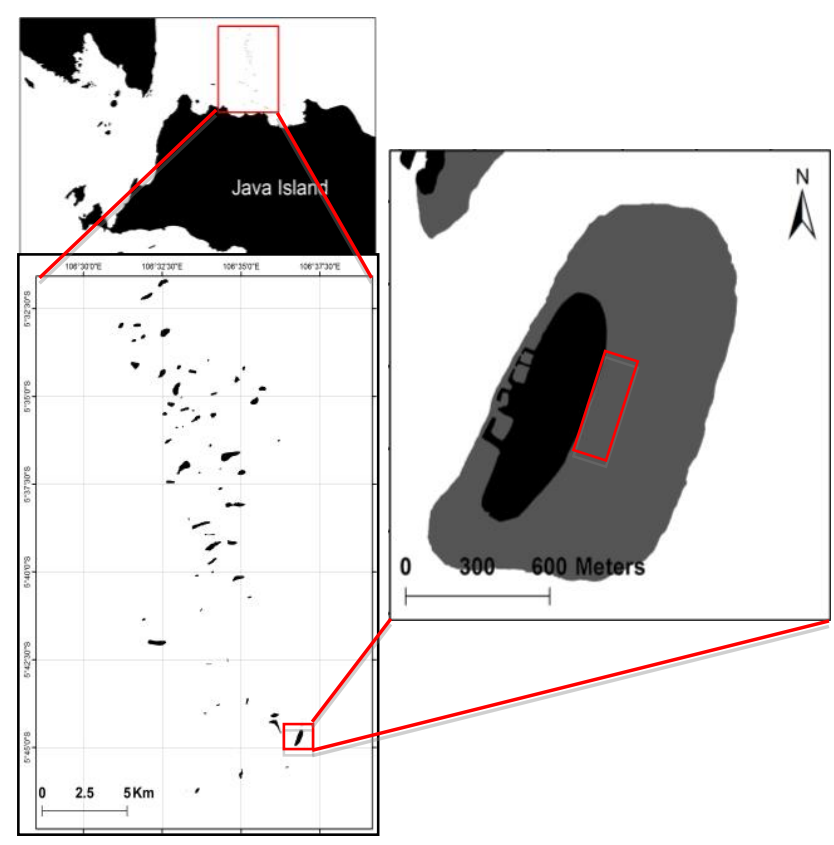

Gambar 1. Lokasi penelitian pulau Pramuka, kepulauan Seribu.

\section{Hasil dan Pembahasan}

\subsection{Keanekaragaman dan kepadatan gastropoda}

Hasil pengamatan pada 7 plot kuadrat yang diletakkan secara acak di area mangrove pulau Pramuka, keanekaragaman gastropoda ditemukan 2 jenis yang tersebar pada ketinggian 0-3 m (Tabel 1). Nilai keanekaragaman gastropoda di ketinggian 0-1 m memiliki nilai 0.6 dan 0 untuk ketinggian 1 sampai dengan $3 \mathrm{~m}$ (Tabel 1). Kepadatan gastropoda jenis Littorina sp. ditemukan pada semua ketinggian yaitu pada ketinggian $0-1 \mathrm{~m}$ sebanyak $7.8 \pm 5.0 \mathrm{ind} / \mathrm{m}^{2}$, ketinggian $1-2 \mathrm{~m}$ sebanyak $3.75 \pm 2.7 \mathrm{ind} / \mathrm{m}^{2}$, dan ketinggian $2-3 \mathrm{~m}$ sebanyak $5 \mathrm{ind} / \mathrm{m}^{2}$. Sedangkan jenis Terebralia $\mathrm{sp}$. hanya ditemukan pada ketinggian $0-1 \mathrm{~m}$ sebanyak $14.75 \pm 8.0$ individu.

\section{Tabel 1}

Kepadatan dan keanekaragaman gastropoda di mangrove Rhizophora stylosa (ind $\left./ \mathrm{m}^{2}\right)$.

\begin{tabular}{ccccc}
\hline \multirow{2}{*}{ Famili } & Jenis & \multicolumn{3}{c}{ Ketinggian Mangrove (m) } \\
\cline { 3 - 5 } & & $\mathbf{0 - 1}$ & $\mathbf{1 - 2}$ & $\mathbf{2 - 3}$ \\
\hline Littorinidae & Littorina sp. & $7.8 \pm 5.0$ & $3.75 \pm 2.7$ & 5 \\
Potamididae & Terebralia sp. & $14.75 \pm 8.0$ & 0 & 0 \\
\hline Keanekaragaman & & & \\
\hline H' $^{\prime}$ & 0.6 & 0 & 0 \\
\hline
\end{tabular}


Gastropoda di ekosistem mangrove pulau Pramuka berdekatan dengan ekosistem lamun. Gastropoda dapat ditemukan di habitat ekosistem mangrove sampai dengan perbatasan ekosistem lamun (Pape et al., 2008). Keanekaragaman pada ketinggian $0-1 \mathrm{~m}$ memiliki nilai yang lebih tinggi dibandingkan dengan yang lain. Hasil penelitian Macintosh et al., (2002), menunjukkan bahwa nilai keanekaragaman gastropoda di ekosistem mangrove tanam lebih rendah dibandingkan dengan alami dan cenderung dominan untuk spesies tertentu. Faktor pasang surut, sumber makanan (Blanco dan Cantera, 1999), reproduksi, agregasi (Alfaro, 2007), umur mangrove, tinggi pohon, basal area dan kimia fisik lingkungan (Macintosh et al., 2002) dapat mempengaruhi jumlah spesies dan individu di ekosistem mangrove.

Umur dan kepadatan dari mangrove sendiri juga dapat mempengaruhi komunitas gastropoda yang ada. Hasil penelitian Macintosh et al., (2002), menunjukkan bahwa jenis dari famili Littorinidae memiliki keanekaragaman dan kepadatan yang tinggi pada mangrove tanam yang masih muda dan kecil (4-5tahun). Littorinidae ditemukan lebih sedikit pada tanaman yang lebih tua (7 tahun) dan tidak ditemukan pada hutan mangrove yang lebih tua. Hal ini sesuai pengamatan, dimana jenis dari famili Littorinidae banyak ditemukan di area mangrove tanam pulau Pramuka yang memiliki kepadatan yang tinggi dan umur yang masih muda.

Gastropoda Terebralia sp. merupakan jenis yang paling banyak ditemukan di mangrove tanam pulau Pramuka. Jenis Terebralia sp. adalah salah satu jenis yang banyak ditemukan pada substrat pasir maupun lumpur pada area mangrove (Fratini et al., 2004; Pape et al., 2008) Menurut Fratini et al. (2004), Terebralia palustris (Potamididae) menyukai habitat yang memiliki substrat dengan kandungan organik tinggi dan produksi sampah daun yang tinggi pada area mangrove. Mangrove tanam di pulau Pramuka yang memiliki kepadatan tinggi (jarak tanam $0,5 \mathrm{~m}$ ), diduga akan menghasilkan sampah daun yang cukup banyak. Sehingga jenis ini akan banyak ditemukan pada lokasi area mangrove tanam.

\subsection{Distribusi vertikal dan ukuran cangkang gastropoda}

Distribusi vertikal gastropoda di ekosistem mangrove pulau Pramuka memiliki perbedaan yang nyata $(\mathrm{p}<0.05)$ di setiap ketinggian dengan ukuran cangkang yang beragam (Gambar 2). Jenis Littorina sp. yang ditemukan pada ketinggian 1-2 m memiliki panjang total yang lebih tinggi dibandingkan dengan $0-1 \mathrm{~m}$ dan 2-3 m. Nilai panjang total Littorina sp. yang lebih tinggi dimulai 1.92, 1.72 dan $1.46 \mathrm{~cm}$, secara berurutan. Lebar total Littorina sp. memiliki nilai dari yang lebih tinggi yaitu 0.98, 0.97 dan $0.96 \mathrm{~cm}$, secara berurutan. Littorina sp. memiliki nilai $0.77,0.75$ dan $0.72 \mathrm{~cm}$ untuk panjang aperture dan 0.64 , 0.63 dan $0.60 \mathrm{~cm}$ untuk lebar aperture, secara berurutan. Jenis Terebralia sp. yang ditemukan pada ketinggian 0-1 $\mathrm{m}$ memiliki ukuran panjang total cangkang $2.11 \mathrm{~cm}$, lebar total $0.96 \mathrm{~cm}$, panjang aperture $0.77 \mathrm{~cm}$ dan lebar aperture $0.59 \mathrm{~cm}$.

Hasil pengamatan distribusi vertikal, gastropoda ditemukan bahwa jenis Littorina sp. ditemukan pada ketinggian 0 sampai dengan $3 \mathrm{~m}$. Jenis ini jarang ditemukan pada dasar substrat dan kebanyakan ditemukan tidak kurang dari 0.2-0.5 m diatas substrat dasar. Pada saat surut rendah jenis ini ditemukan pada batang rendah mangrove, namun tidak dapat pada substrat disekitar pohon mangrove. Distribusi vertikal dari jenis Littorina sp. dipengaruhi oleh sumber makanan, siklus pasang air laut, repoduksi dan agregasi pada saat distribusi (Alfaro, 2007). Menurut Reid (1985), Littorina sp. ditemukan melimpah pada daerah hutan pinggir pantai, dimana banyak terdapat pohon dari genus Avicennia dan Rhizophora. Selain itu, jenis Littorina sp. dapat ditemukan di mangrove ukuran kecil sampai dengan tinggi (Tanaka dan Maia, 2006). Berdasarkan ukuran cangkang Terebralia sp. yang ditemukan pada area mangrove tanam pulau Pramuka masih tergolong juvenile. Perubahan bentuk dari juvenile menjadi dewasa terjadi pada saat panjang total cangkang mencapai 5-6 cm (Fratini et al., 2004).

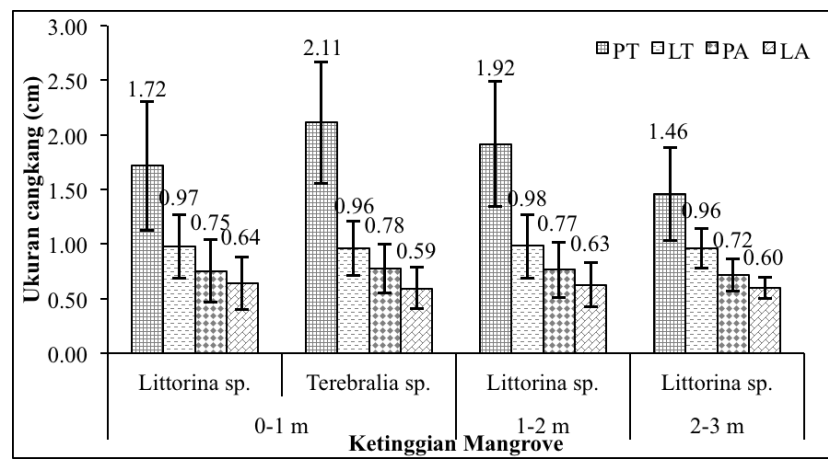

Gambar 2. Rata-rata ukuran cangkang gastropoda yang ditemukan pada setiap ketinggian. Keterangan: PT (Panjang Total), LT (Lebar Total), PA (Panjang Aperture), LA (Lebar Aperture)

Distibusi vertikal memiliki hubungan dengan jumlah individu gastropoda (Gambar 3) dan memiliki hubungan dengan ukurang panjang total cangkang (Gambar 4). Ratarata cangkang gastropoda memiliki ukuran lebih panjang di ketinggian 0 sampai 2 dibandingkan dengan $3 \mathrm{~m}$. Gastropoda yang memiliki ukuran cangkang yang lebih panjang ditemukan pada spesies Terebralia sp.

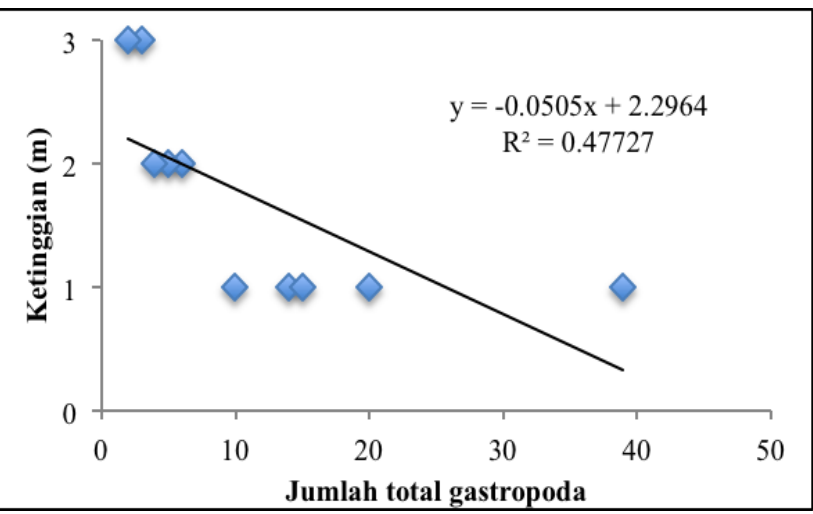

Gambar 3. Regresi linear distribusi vertikal dengan jumlah individu gastropoda.

Gastropoda di ekosistem mangrove pulau Pramuka lebih banyak ditemukan pada ketinggian 0-1 m yaitu di sedimen mangrove. Menurut Fratini et al., (2004) dan 
Pape et al., (2008), bahwa gastropoda lebih banyak ditemukan di sedimen mangrove dengan jenis Potamididae dan Littorinidae. Jumlah Potamididae yang melimpah karena dipengaruhi oleh bentuk vegetasi mangrove (Pape et al., 2008), salinitas, penutupan kanopi, $\mathrm{pH}$, kandungan organik, waktu atau jam (Fratini et al., 2004) dan sumber makanan (Wardiatno et al., 2015). Selain gastropoda, dapat ditemukan biota dari kelas ikan, cacing, bivalvia (Al-Khayat dan Jones 1999) dan kepiting (Macintosh et al., 2002; Wardiatno et al., 2015).

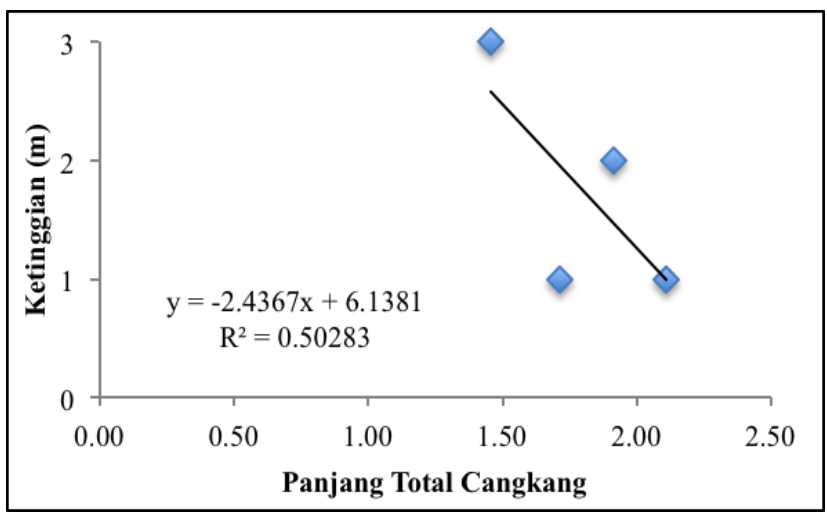

Gambar 4. Regresi linear distribusi vertikal dengan panjang total cangkang.

Hasil dari regresi linear distribusi vertikal dengan panjang total cangkang menunjukkan bahwa semakin tinggi wilayah distribusi gastropoda makan semakin pendek cangkang gastropoda. Hal ini karena pengaruh dari distribusi jenis gastropoda dimana yang paling banyak ditemukan di ketinggian dibawah $1 \mathrm{~m}$ adalah jenis gastropoda yang memiliki cangkang lebih panjang. Penelitian Tanaka dan Maia (2006) menunjukkan bahwa cangkang yang panjang dapat ditemukan di ketinggian mangrove yang pendek sampai dengan tinggi. Lebih lanjut, gastropoda dari jenis Littorina yang memiliki panjang aperture dan cangkang ditemukan pada ketinggian rendah dan tinggi. Perbedaan panjang cangkang dan aperture di ketinggian yang berbeda karena pengaruh pasang surut.

Perilaku makan dari Terebralia sp. diduga mempengaruhi distribusi di ekosistem mangrove. Hasil penelitian Fratini et al., (2004), menunjukkan bahwa gastropoda dewasa memiliki pakan utama berupa sampah daun mangrove yang sudah tua dan jatuh ke dasar, sedangkan kategori juvenile lebih memilih pakan utama berupa lumpur dan material organik. Hal ini menyebabkan Terebralia sp. hanya ditemukan pada ketingian 0-1 m, dimana pakan utama dari siput ini banyak tersedia. Selain itu, distribusi gastropoda di ekosistem mangrove dipengaruhi pasang surut, sumber makanan (Blanco dan Cantera, 1999) dan menghindari dari predator (Duncan dan Szelistowski, 1998; Tupan, 2009).

\subsection{Penilaian ekosistem mangrove}

Penanaman mangrove yang ada di pulau Pramuka secara langsung telah mempengaruhi kondisi ekosistem yang ada. Penambahan vegetasi pada daerah pantai tentunya akan mempengaruhi karakteristik lingkungan dan berpengaruh terhadap keberadaan hewan bentik yang mendiami ekosistem sebelumnya. Hasil penelitian sebelumnya tentang respon hewan bentik dengan struktur mangrove, terdapat perubahan pada karakteristik lingkungan (salinits, $\mathrm{pH}$, persen lumpur, luas pasangsurut) yang sejalan dengan perubahan struktur hutan, komposisi jenis pohon dan struktur komunitas bentos (Ellison, 2008). Menurut Al-Khayat dan Jones (1999), mangrove tanam dengan alami memiliki perbedaan seperti ukuran sedimen dan $\mathrm{pH}$ yang tinggi, tetapi rendah bahan organik dan kandungan air.

Hasil pengamatan terhadap keberadaan gastropoda di ekosistem mangrove hasil tanam di pulau Pramuka menunjukkan bahwa ekosistem mangrove tersebut tergolong masih muda dan masih dalam masa transisi. Hal ini terlihat dari hanya terdapat dua genus gastropoda yang ditemukan. Penelitian Macintosh et al., (2002) dan Ernawati dkk., (2013) menunjukkan bahwa terdapat perbedaan struktur komunitas kepiting dan moluska antara daerah rehabilitasi dan hutan mangrove yang sudah tua. Nilai indeks keanekaragaman jenis lebih tinggi pada hutan mangrove yang sudah tua dibandingkan daerah hasil rehabilitasi penanaman mangrove yang masih muda (Bosire et al., 2008; Ernawati dkk., 2013). Hal ini disebabkan hutan mangrove yang sudah tua memiliki habitat yang lebih beragam dan struktur sedimen yang sudah baik (Al-Khayat dan Jones 1999). Hasil penelitian Zvonareva et al., (2015) menunjukkan bahwa terdapat perbedaan jumlah gastropoda di mangrove tanam dengan yang alami karena mangrove hasil tanam belum seimbang dan dalam masa transisi.

Mangrove tanam di pulau Pramuka merupakan monokultur dari jenis Rhizophora stylosa. Pemilihan mangrove dari jenis ini sebagai mangrove tanam dianggap sudah tepat, hal ini dikarenakan pulau Pramuka termasuk ke dalam kawasan padat penduduk. Penduduk yang padat akan menghasilkan masalah sampah yang tidak terhindarkan. Untuk daerah yang memiliki karakteristik banyak sampah plastik, disarankan untuk menanam mangrove yang memiliki perakaran luas seperti dari jenis Rhizophora. Perakaran mangrove tersebut dapat menangkap sampah plastik yang terbawa arus (Gorman dan Turra, 2016).

Penanaman mangrove diharapkan juga memperhatikan fungsi habitat dan keberadaan dari makrofauna yang mendiami ekosistem tersebut. Hutan mangrove monokultur seperti di pulau Pramuka diduga akan menimbulkan degradasi jenis makrofauna yang mendiami ekosistem tersebut. Komposisi, kelimpahan, keanekaragaman, dan biomassa krustasea dan moluska akan berbeda pada hutan mangrove yang memiliki beberapa jenis pohon dibandingkan dengan daerah hutan mangrove monokultur (Macintosh et al., 2002). Berdasarkan hal tersebut, masyarakat diharapkan lebih memperhatikan dan memberikan penilaian terlebih dahulu terhadap fungsi hutan mangrove sebelum melakukan reboisasi maupun restorasi habitat.

\section{Simpulan}

Keberadaan gastropoda di ekosistem mangrove pulau Pramuka memiliki keanekaragaman dan kepadatan yang rendah dibandingkan dengan yang lain. Gastropoda yang 
paling banyak ditemukan pada ketinggian 0-1 $\mathrm{m}$ dan memiliki cangkang yang besar dari jenis Terebralia sp., yang memiliki distribusi yang luas (dari 0 sampai dengan $3 \mathrm{~m}$ ) adalah dari jenis Littorina sp. Gastropoda di pulau Pramuka menunjukkan bahwa mangrove hasil tanam tergolong masih muda dan masih dalam masa transisi. Penanaman jenis mangrove perlu diperhatikan, karena pemilihan jenis yang baik akan mempengaruhi faktor biotik dan abiotik ekosistem mangrove.

\section{Ucapan terimakasih}

Terimakasih kepada Taman Nasional Kepulauan Seribu (TNKpS) yang telah memberikan waktu dan tempat selama penelitian ini berlangsung. Terimakasih kepada Herwandi dan Firdaus Ramadhan yang telah membantu dalam penelitian ini.

\section{Daftar Pustaka}

Abbott, R. T., \& Dance, S. P. (1986). Compendium of Seashells. El Cajon, California, US: Odyssey Publishing.

Alfaro, A. C. (2007). Migration and trail affinity of snails, Littoraria scabra, on mangrove trees of Nananu-i-ra, Fiji Islands. Marine and Freshwater Behaviour and Physiology, 40(4), 247-255.

Al-Khayat, J. A., \& Jones, D. A. (1999). A comparison of the macrofauna of natural and replanted mangroves in Qatar. Estuarine, Coastal and Shelf Science, 49, 55-63.

Blanco, J. F., \& Cantera, J. R. (1999). The vertical distribution of mangrove gastropods and environmental factors relative to tide level at Buenaventura Bay, Pacific Coast of Colombia. Bulletin of marine science, 65(3), 617-630.

Bosire, J. O., Dahdouh-Guebas, F., Walton, M., Crona, B. I., Lewis, R. R., Field, C., Kairo, J. G., \& Koedam, N. (2008). Functionality of restored mangroves: a review. Aquatic Botany, 89(2), 251-259.

BPS. 2016. Kepulauan Seribu Dalam Angka. Jakarta-Indonesia: Badan Pusat Statistik Kabupaten Kepulauan Seribu.

Daru, B. H., Yessoufou, K., Mankga, L. T., \& Davies, T. J. (2013). A global trend towards the loss of evolutionarily unique species in mangrove ecosystems. PLoS One, 8(6), e66686.

Dharma, B. 1988. Siput dan Kerang Indonesia I (Indonesia Shells). Jakarta-Indonesia: Sarana Graha.

Duncan, R. S., \& Szelistowski, W. A. (1998). Influence of puffer predation on vertical distribution of mangrove littorinids in the Gulf of Nicoya, Costa Rica. Oecologia, 117(3), 433-442.

Ellison, A. M. (2008). Managing mangroves with benthic biodiversity in mind: moving beyond roving banditry. Journal of Sea Research, 59(1), 2-15.

Ernawati, S. K., Andi, N., Natsir, N. M., \& Bin, A. O. S. (2013). Suksesi Makroozobentos di Hutan Mangrove Alami dan Rehabilitasi di Kabupaten Sinjai Sulawesi Selatan. Bionature, 14(1), 49-60.

Fratini, S., Vigiani, V., Vannini, M., \& Cannicci, S. (2004). Terebralia palustris (Gastropoda; Potamididae) in a Kenyan mangal: size structure, distribution and impact on the consumption of leaf litter. Marine Biology, 144(6), 11731182.
Field, C. B., Osborn, J. G., Hoffman, L. L., Polsenberg, J. F., Ackerly, D. D., Berry, J. A., Bjorkman, O., Held, A., Matson, P. A., \& Mooney, H. A. (1998). Mangrove biodiversity and ecosystem function. Global Ecology \& Biogeography Letters, 7(1), 3-14.

Field, C. (1996). Restoration of mangrove ecosystems. Okinawa, Japan: International Society for Mangrove Ecosystems.

Gorman, D., \& Turra, A. (2016). The role of mangrove revegetation as a means of restoring macrofaunal communities along degraded coasts. Science of the Total Environment, 566, 223-229.

Hogarth, P.J. (2007). The Biology of Mangroves and Seagrasses. $\left(2^{\text {nd }}\right.$ Ed. $)$. New York-US: Oxford University Press.

Kathiresan, K., \& Bingham, B. L. (2001). Biology of mangroves and mangrove ecosystems. Advances in marine biology, $\mathbf{4 0}$, 81-251.

Macintosh, D. J., Ashton, E. C., \& Havanon, S. (2002). Mangrove rehabilitation and intertidal biodiversity: a study in the Ranong mangrove ecosystem, Thailand. Estuarine, Coastal and Shelf Science, 55(3), 331-345.

Nagelkerken, I., Blaber, S. J. M., Bouillon, S., Green, P., Haywood, M., Kirton, L. G., Meynecke, J. O., Pawlik, J., Penrose, H. M., Sasekumar, A., \& Somerfield, P. J. (2008). The habitat function of mangroves for terrestrial and marine fauna: a review. Aquatic Botany, 89(2), 155-185.

Pape, E., Muthumbi, A., Kamanu, C. P., \& Vanreusel, A. (2008). Size-dependent distribution and feeding habits of Terebralia palustris in mangrove habitats of Gazi Bay, Kenya. Estuarine, Coastal and Shelf Science, 76(4), 797-808.

Polidoro, B. A., Carpenter, K. E., Collins, L., Duke, N. C., Ellison, A. M., Ellison, J. C., Farnsworth, E. J., Fernando, E. S., Kathiresan, K., Koedam, N. E., Livingstone, S. R., Miyagi, T., Moore, G. E., Nam, V. N., Ong, J. E., Primavera, J. H., Salmo III, S. G., Sanciangco, J. C., Sukardjo, S., Wang, Y., \& Yong, J. W. H. (2010). The loss of species: mangrove extinction risk and geographic areas of global concern. PloS One, 5(4), e10095.

Poutiers, J. M. (1998). Gastropods. In: Carpenter, K. E., Niem, V. H. (Eds.), The Living Marine Resources of the Western Central Pacific - Volume 1: Seaweeds, corals, bivalves and gastropods. Roma-Italia: Food and Agriculture Organization of the United Nations, pp. 363-646.

Reid, D. G. (1985). Habitat and zonation patterns of Littoraria species (Gastropoda: Littorinidae) in Indo - Pacific mangrove forests. Biological Journal of the Linnean Society, 26(1), 3968.

Tanaka, M. O., \& Maia, R. C. (2006). Shell morphological variation of Littoraria angulifera among and within mangroves in NE Brazil. Hydrobiologia, 559, 193-202.

Tupan, C. I. (2009). Tingkah laku pergerakan gastropoda Littorina scabra pada pohon mangrove Sonneratia alba di perairan Pantai Tawiri, Pulau Ambon. Triton : Jurnal Manajemen Sumberdaya Perairan, 5(1), 28-33.

Wardiatno, Y., Mardiansyah, T. P., \& Tsuchiya, M. (2015). Possible food sources of macrozoobenthos in the Manko mangrove ecosystem, Okinawa (Japan): a stable isotope analysis approach. Tropical life sciences research, 26(1), 5365 .

Zvonareva, S., Kantor, Y., Li, X., \& Britayev, T. (2015). Longterm monitoring of Gastropoda (Mollusca) fauna in planted mangroves in central Vietnam. Zoological Studies, 54, 39(116).

(C) 2016 by the authors; licensee Udayana University, Indonesia. This article is an open access article distributed under the terms and conditions of the Creative Commons Attribution license (http://creativecommons.org/licenses/by/3.0/). 